\title{
Nesiritide protects endothelial function after balloon- induced trauma in the iliac artery in rabbits
}

\author{
Shu-Qin Liu',2, Li-Ping Zhang'2, Huan-Ying Yan², \\ Xing-Hua Zhang ${ }^{1^{*}}$, Le-Xin Wang ${ }^{\left(2,3^{*}\right.}$ \\ ${ }^{1}$ Department of Cardiology, Shandong Provincial Hospital affiliated to Shandong \\ University, Jinan, Shandong Province, China, ${ }^{2}$ Department of Cardiology, Liaocheng \\ People's Hospital, Liaocheng, Shandong Province, China, ${ }^{3}$ School of Biomedical \\ Sciences, Charles Sturt University, Wagga Wagga, NSW, Australia
}

\begin{abstract}
To assess the effect of nesiritide on the endothelial function of iliac arteries following endothelia trauma. Right iliac artery trauma was created with a balloon catheter. Ten rabbits were treated with a 4-week subcutaneous injection of nesiritide at a fixed daily dose of $0.1 \mathrm{mg} / \mathrm{kg}$. Ten rabbits received daily normal saline injection. Plasma endothelin 1 (ET-1), nitric oxide (NO), and Von Willebrand Factor (vWF) were measured before and after the therapies. Tissue proliferating cell nuclear antigen (PCNA) was measured after the treatment. After the treatment, in the therapeutic group, the area under internal elastic membrane and the residual lumen area were higher than in the normal saline group $(\mathrm{P}<0.05)$. The plasma levels of ET-1 $(91.6 \pm 6.8 \mathrm{vs} 114.9 \pm 6.3 \mathrm{ng} / \mathrm{L}, \mathrm{P}=0.001)$, vWF $(134.6 \pm 10.8 \%$ vs $188.8 \pm 10.4 \%, \mathrm{P}=0.001)$ and the ratio of PCNA positive expression $(11.7 \pm 4.2 \%$ vs $36.2 \pm 11.4 \%, \mathrm{P}$ $=0.005)$ in the therapeutic group was lower than in the normal saline group, while the plasma levels of $\mathrm{NO}$ was higher $(89.7 \pm 9.3$ vs $43.5 \pm 5.3 \mu \mathrm{mol} / \mathrm{L}, \mathrm{P}=0.001)$. Nesiritide inhibited remodeling of rabbit iliac artery following endothelial trauma. The inhibition of vascular remodeling may be related to the alleviated endothelial dysfunction and reduced expression of tissue proliferating cell nuclear antigen.
\end{abstract}

Keywords: Plasma endothelin (ET-1). Nitric oxide (NO). von Willebrand Factor (vWF). Tissue proliferating cell nuclear antigen. Iliac artery.

\section{INTRODUCTION}

The B-type natriuretic peptide (BNP) is a vasoactive peptide. After more than two decades of active investigations, BNP has become a useful biomarker for the diagnosis of congestive heart failure and risk stratification of this prevalent and chronic condition (Egom, 2015; We et al. 2005a, 2005b, 2005c; Sun et al., 2007). BNP exerts protective effects against the post-myocardial infarction remodeling processes. In rats, BNP treatment inhibits extracellularmatrix remodeling following acutemyocardial

*Correspondence: X.-H. Zhang, Department of Cardiology, Shandong Provincial Hospital, Shandong University, No. 324, Jinan 250021, China. Email: 13969548581@163.com. L. Wang, Department of Cardiology, Liaocheng People's Hospital, Liaocheng 252000, Shandong Province, China. Email: 1wang@csu.edu.au infarction, and preserves ventricular function (Pan et al., 2011; Plante et al. 2014). BNP plays an important role in modulating vascular endothelial function, and predicts the endothelial function in human subjects (Menon et al., 2009; Pauriah et al., 2012). Nesiritide, a synthetic BNP, has been used to treat acute decompensated heart failure for more than a decade (Chen et al., 2013). Currently, there is a lack of understanding about the associations between nesiritide and vascular endothelial function. In human subjects, nesiritide treatment has been shown to suppress fibrosis and hypertrophy in the myocardium, and reduce end-diastolic volume a month after the treatment (Chen et al., 2009). In a porcine model of acute myocardial infarction, nesiritide infusion reduced the size of infarct and preserved coronary endothelial function (Lazar et al., 2009). 
Our previous studies in a rabbit model have found that nesiritide treatment inhibited vascular remodeling following arterial injuries, and the improved remodeling profile was due to reduced plasma aldosterone levels (Liu et al., 2010, 2012). However, it is unclear if nesiritide can protect injuryinduced endothelial dysfunction. Endothelin-1 (ET-1) is an endogenous vasoconstrictor that is involved in systemic and pulmonary hypertension. It also impacts on cardiac function and is associated with a higher mortality rate in patients with heart failure (Perez et al., 2016). Nitric oxide (NO) is an endogenous vasodilator that regulates systemic and pulmonary circulation, as well as cardiovascular remodeling (Chen et al., 2014). von Willebrand Factor (vWF) is a molecule that is released from the vascular endothelium, leading to hypercoagulability and thrombosis. Balloon dilation of peripheral arteries were associated with an elevation in blood vWF (Yao, Wang, Kang, 2016).

Although BNP has been shown to improve endothelial function in a variety of chronic cardiovascular conditions, the impact of nesiritide treatment on plasma ET-1, NO, and vWF following vascular injuries has not been reported. In this study, we investigated the changes in plasma ET-1, NO, vWF and neointimal proliferation following nesiritide therapy in a rabbit model that we have previously reported (Liu et al., 2010, 2012).

\section{MATERIAL AND METHODS}

\section{Induction of arterial trauma}

The Animal Ethics Committee of our hospital approved the present study, and the study protocols have followed the national guidelines. All steps have been taken to minimize the animals' pain and suffering during and after the operations. A total of 20 male rabbits were used for this study. The weight of the animals was $2.3 \pm 0.2 \mathrm{~kg}(2.1-2.6 \mathrm{~kg})$, with a median age of 5 months. Arterial trauma was induced with a balloon-catheter (Liu et al., 2010, 2012). First, under room temperature, ketamine $(20 \mathrm{mg} / \mathrm{kg})$ was intravenously injected. Under ultrasound guidance, we inserted a Medtronic balloon catheter (Medtronic, MN, USA) to the common iliac artery where the catheter was inflated to a 5-atmosphere pressure (Liu et al., 2010, 2012) to create trauma to the arterial wall. Subsequently, we divided the animals into two groups, with 10 animals in each group. In one group (the therapeutic group), nesiritide (Shanghai GL Biochen, Shanghai, China) was injected subcutaneously at a daily dose of $0.1 \mathrm{mg} / \mathrm{kg}$ for a total of 4 weeks. This dosage was based on our previous studies in the same animal model, and proved to be the most effective (Liu et al., 2010, 2012). In the control group, normal saline was injected subcutaneously for the same period as the therapeutic group.

\section{Histological studies}

Haematoxylin and Eosin (HE) staining was used to study the vascular tissues which were collected at the end of the experiments (Liu et al., 2010, 2012). Tissue sections were studied by an imaging system (model ES2050, WD Technologies, Beijing, China). In each sections of the iliac artery, the area under internal elastic membrane (AUIEM), intimal area and residual lumen area were measured by two independent pathologists. The ratio of stenosis of the iliac artery was calculated by (AUIEM-residual lumen area)/AUIEM.

\section{Plasma endothelin-1 (ET-1), nitric oxide (NO), and von Willebran factor (vWF)}

Plasma ET-1 and vWF were measured by enzymelinked immunosorbent assay (ELISA). Plasma NO was measured by a nitrate reduction method. A commercial ELISA kit (Bogoo Biological Engineering Co, Shanghai, China) was used for ET-1 and vWF measurement. The NO kit was provided by Jiancheng Institute of Biological Engineering (Nanjing, China).

\section{Immunohistochemistry for proliferating cell nuclear antigen (PCNA)}

A commercially available immunohistochemistry kit (Boster Biological Engineering, Wuhan, China) was used to determine PCNA in the vascular tissues. Vascular tissue sections were stained with mouse antirabbit PCNA antibodies, and the slides were examined by optical microscope $(\times 200)$. All cells in each of the 10 visual fields, including the cells with positive PCNA expression (brown stains) were counted and recorded manually. The ratio between PCNA positive cells and total cells was defined as the positive PCNA expression rate. Two readers performed the cell counts and the means of the two sets of readings were used as the results. 


\section{Statistical analysis}

SPSS software (Version 13, IBM SPSS Statistics, NY, USA) was used in thestatistical analysis of data. Data expression was in the form of means \pm standard deviation. Numerical data and categorical data were analyzed by an independent student's $t$ and Fisher's exact test, respectively. Statistical significance was determined at $\mathrm{p} \leq 0.05$.

\section{RESULTS}

\section{Effect of nesiritide on the structure of the iliac arteries}

The two remodeling measures (AUIEM and residual lumen areas) in the control animals were lower than the therapeutic group animals $(\mathrm{P}=0.025$ and $\mathrm{P}$ $=0.001$, respectively, Table I), whereas the stenosis ratio in the study group was higher $(\mathrm{P}=0.001$, Table I).

TABLE I - Comparison of remodeling indices between nesiritide and control group

\begin{tabular}{lccc}
\hline & $\begin{array}{c}\text { Control } \\
(\mathbf{n}=10)\end{array}$ & $\begin{array}{c}\text { Nesiritide } \\
(\mathbf{n = 1 0})\end{array}$ & $\mathbf{P}$ \\
\hline AUIEM $\left(\mu \mathrm{m}^{2}\right)$ & $493.7 \pm 139.3$ & $643.2 \pm 134.1$ & 0.025 \\
Intimal area $\left(\mu \mathrm{m}^{2}\right)$ & $185.1 \pm 75.05$ & $124.1 \pm 61.5$ & 0.062 \\
$\begin{array}{l}\text { Residual lumen } \\
\text { area }\left(\mu \mathrm{m}^{2}\right)\end{array}$ & $308.6 \pm 86.5$ & $519.1 \pm 93.5$ & 0.001 \\
Stenosis ratio $(\%)$ & $37.1 \pm 9.2$ & $18.54 \pm 7.8$ & 0.001 \\
\hline
\end{tabular}

AUIEM: area under internal elastic membrane.

\section{PCNA expression in the iliac arteries}

No positive PCNA expression was observed in the tissues of the normal iliac arterial tissues (Figure 1A). Traces of PCNA expression were found in the vascular structures of the animals from the therapeutic group (Figure 1B). However, strong PCNA expression were present in the endothelium, smooth muscles and interstitial cells of the iliac arteries of the control group rabbits (Figure 1C).
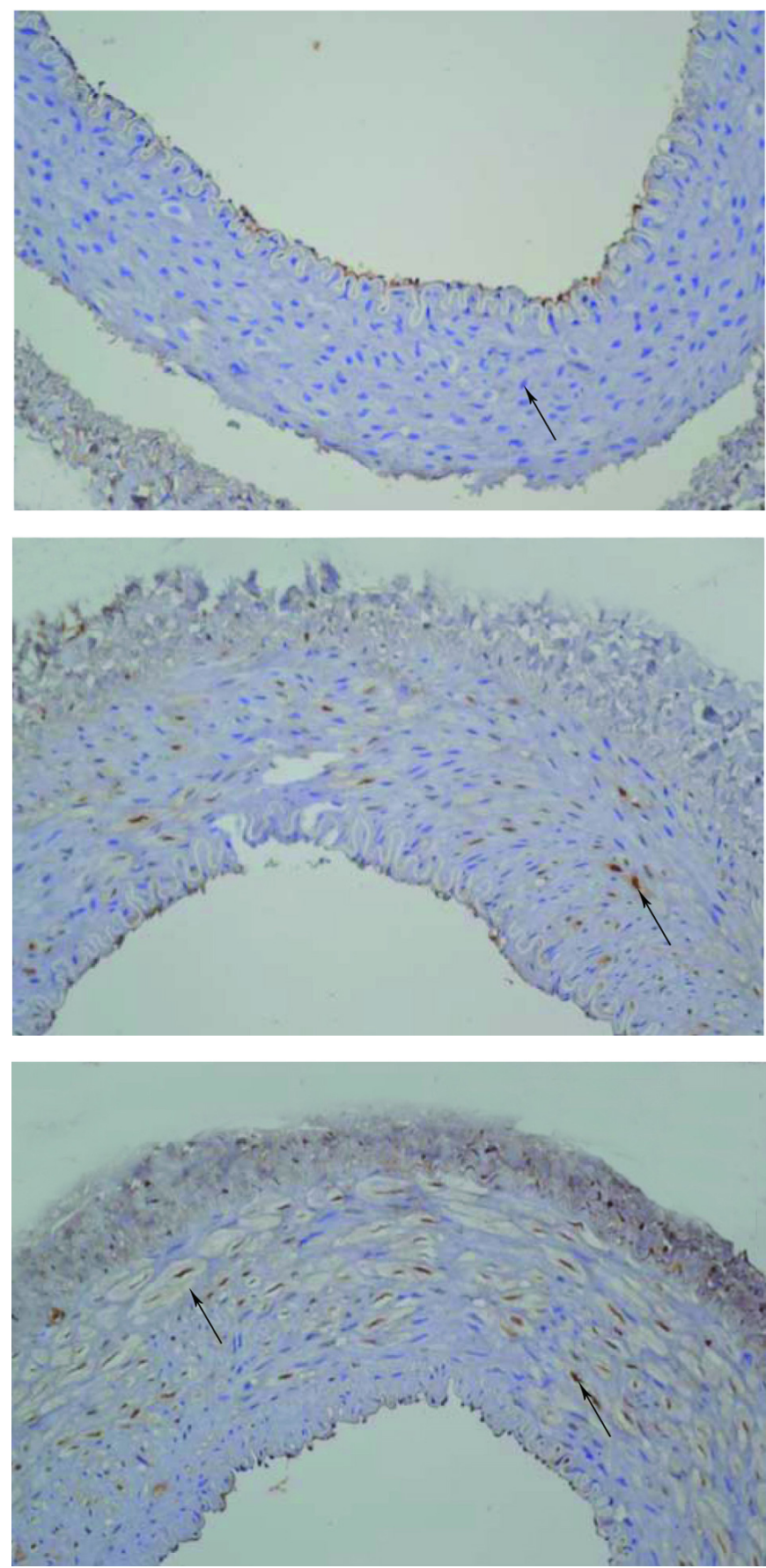

FIGURE 1 - Immunohistochemical PCNA staining $(\times 200)$. Cells stained with brownish color were considered positive. (a) shows tissues from the non-injured left iliac arteries $(n=10)$ from nesiritide group. No PCNA expression was found (arrow). (b) tissues from the injured right iliac artery tissue from the nesiritide group $(n=10)$. Scattered PCNA expression displayed as yellow brown granules (arrow). The positive staining rate was $11.7 \pm 4.2 \%$. (c) tissues from the injured right iliac artery from the control group $(\mathrm{n}=10)$ with dense PCNA expression (arrows). The positive staining rate was $36.0 \pm 11.2 \%(P<0.01$ compared with nesiritide group). 


\section{Plasma levels of ET-1, NO and vWF}

Baseline levels of ET-1, NO and vWF were obtained before the treatment, with no difference observed between the therapeutic and control group rabbits (Table II, P >0.05). In all rabbits, the levels of plasma ET-1 and vWF were increased, while NO levels were decreased at the end of the 28-day treatment. However, the posttreatment levels of plasma ET-1 and vWF levels in the therapeutic group rabbits were lower than the control group rabbits, while the NO levels were significantly higher (Table II, $\mathrm{P}=0.001$ ).

\section{DISCUSSION}

In this experimental work, we found that treatment with nesiritide for four weeks reduced the degree of vascular remodeling in the iliac arteries of the rabbits. We also found that there was a subdued increase in ET-1 and $\mathrm{vWF}$ in the systemic circulation after nesiritide therapies, and a greater elevation in the circulating NO levels. These results suggest that the alleviation in endothelial dysfunction and the improved biosynthesis of NO may be the contributing factors for the therapeutic effect of nesiritide against vascular trauma.

Vascular remodeling is characterized by disordered proliferation and migration of vascular smooth muscle cells, leading to vascular stenosis and tissue ischemia. Vascular remodeling is implicated in several cardiovascular diseases, such as pulmonary hypertension, ventricular hypertrophy, heart failure and myocardial infarction. Endothelium plays a critical role in regulating circulatory and vital organ functions, as well as vascular remodeling after vascular injuries or insults. Endothelial injuries and subsequent dysfunction form the pathological basis of several cardiovascular disorders, such as coronary artery and cerebrovascular disease, which may result in organ failure (Lerman et al., 1991, 1995; Manoury, Montiel, Balligand, 2012; Meyer et al., 2006). Under certain stimulatory conditions, ET-1, NO and vWF are released from the vascular endothelium or vascular walls to exert their regulatory effects. Therefore, the plasma levels of ET$1, \mathrm{NO}$ and vWF can be used as the circulating biomarkers for endothelial function. Elevation of ET-1 and vWF, and decline in NO may reflect endothelial dysfunction (Lerman et al., 1991, 1995; Manoury, Montiel, Balligand, 2012; Meyer et al., 2006).

The main physiological function of ET-1 is to stimulate the growth of vascular smooth muscle cells and cause vasoconstriction (Lerman et al., 1991, 1995). The effects of NO are much more complex. They include vasodilation, inhibition of platelet aggregation, proliferation and migration of smooth muscle cells (Manoury B). NO also prevents cardiovascular trauma or insult, and alleviates vascular remodeling. NO also helps to protect endothelium against physical or chemical injuries (Manoury, Montiel, Balligand, 2012). The physiological or pharmacological roles of vWF are not well understood. It seems vWF helps to clearing out circulating coagulation factor VIII, and is therefore involved in the coagulation processes, particularly in the presence of trauma to the vascular endothelium (Lenting, Christophe, Denis, 2015; Mannucci, 1998).

A number of experimental and clinical studies have demonstrated that BNP can suppress vascular remodeling and improve hemodynamics by improving endothelial function. In cultured pulmonary arterial smooth muscle cells, BNP inhibited proliferation and migration of the

TABLE II - Comparison of plasma ET-1, NO and vWF levels between nesiritide and control group

\begin{tabular}{lccccc}
\hline & \multicolumn{2}{c}{ Control $(\mathbf{n}=10)$} & \multicolumn{2}{c}{ Nesiritide (n=10) } & P (Post-treatment) \\
& Baseline & Post-treatment & Baseline & Post-treatment & \\
\hline $\mathrm{NO}(\mu \mathrm{mol} / \mathrm{L})$ & $95.56 \pm 5.85$ & $43.45 \pm 5.33^{1)}$ & $96.51 \pm 6.48$ & $89.66 \pm 9.25^{1)}$ & 0.001 \\
ET-1 $(\mathrm{ng} / \mathrm{L})$ & $75.71 \pm 5.63$ & $114.93 \pm 6.26^{1)}$ & $74.98 \pm 5.96$ & $91.59 \pm 6.76^{1)}$ & 0.001 \\
vWF $(\%)$ & $102.94 \pm 11.42$ & $188.84 \pm 10.36^{1)}$ & $104.70 \pm 10.56$ & $134.59 \pm 10.81^{1)}$ & 0.001 \\
\hline
\end{tabular}

1) $P<0.01$ compared with baseline value of the same group. NO: nitric oxide; ET-1: endothelium 1; vWF: Von Willebrand factor 
cells induced by angiotensin II (Hsu et al., 2014). BNP also inhibits angiotensin II or ET-1 induced ventricular hypertrophy (Volpe, 2014). Treatment with BNP for four weeks was associated with a reduced endothelial expression of vascular endothelial growth factor, and reduced stenosis after vascular injuries (Liu et al., 2010). Furthermore, intravenous infusion of a BNP, such as nesiritide, decreased pulmonary capillary wedge pressure, which is beneficial to the treatment of acute decompensated heart failure (Volpe, 2014).

In the present study, we found that nesiritide therapies diminished the degree of the remodeling of the iliac artery following physical trauma to the blood vessels. Furthermore, nesiritide therapies was associated with a greater reduction in circulatory ET-1 and vWF levels, and a greater elevation in the NO levels. These results indicate that nesiritide improved the endothelial function after the vascular trauma, which may have contributed to the attenuated vascular remodeling in the injured iliac arteries.

Tissue PCNA expression is a result of cell proliferation. Therefore, the levels of tissue PCNA have been used as a marker for cell proliferation (Suzuki et al., 2000). Other investigators have found that, in a rat model of vascular trauma, overexpression of PCNA was present in thickened neointima of the damaged blood vessels (Wei et al., 1997). In the present study on a rabbit model, no PCNA expression was found in the normal iliac arteries. However, PCNA expression was identified in the traumatized iliac arteries, with a higher PCNA expression identified in the control group rabbits. These results suggest that nesiritide may have inhibited neointimal proliferation and vascular remodeling by suppressing vascular smooth muscle proliferation.

It remains unclear as to how nesiritide treatment reduced the plasma levels of ET-1 and vWF, and increased NO levels in our rabbit model of traumatic iliac artery injuries. Several animal and human studies have confirmed that natriuretic peptides stimulate NO production through the natriuretic peptide clearance receptor (NPR-C) (Houben et al., 2005). Stimulation of this NPR-C receptor decreased cAMP levels by adenylyl cyclase inhibition through an inhibitory guanine nucleotide-regulating protein (Houben et al., 2005). However, there is limited information about the cellular or molecular mechanisms by which brain natriuretic peptides or nesiritide influenced the endothelial expression of ET-1 or vWF. Therefore, further studies in this area are warranted.

\section{CONCLUSIONS}

In this rabbit model, nesiritide improved endothelial function and inhibited neointima proliferation. The improved vascular remodeling following nesiritide treatment are associated with an elevated plasma levels of NO, and reduced levels of ET-1 and vWF, and reduced expression of PCNA in the vascular tissues. These novel results may have several potential clinical implications. Prophylactic treatment with nesiritide may reduce neointima proliferation or endothelial dysfunction following percutaneous coronary intervention (PCI), and diminish post-PCI coronary restenosis. Nesiritide may also be used to prevent vascular trauma from chronic insults, such as diabetes mellitus or hypertension, preventing ischemic injuries to vital organs such as kidneys or the heart. However, these potential clinical benefits require further investigations.

There was no conflict of interest to declare.

\section{REFERENCES}

Chen HH, Anstrom KJ, Givertz MM, Stevenson LW, Semigran MJ, Goldsmith SR. NHLBI Heart Failure Clinical Research Network. Low-dose dopamine or low-dose nesiritide in acute heart failure with renal dysfunction: the ROSE acute heart failure randomized trial. JAMA. 2013;310(23):2533-43.

Chen HH, Martin FL, Gibbons RJ, Schirger JA, Wright RS, Schears RM, Redfield MM, Simari RD, Lerman A, Cataliotti A, Burnett JC Jr. Low-dose nesiritide in human anterior myocardial infarction suppresses aldosterone and preserves ventricular function and structure: a proof of concept study. Heart. 2009;95(16):1315-9.

Chen HY, Strappe P, Chen SF, Wang X. Endothelial progenitor cells and pulmonary arterial hypertension. Heart Lung Circ. 2014;23:595-601.

Egom EE. BNP and heart failure: preclinical and clinical trial data. J Cardiovasc Translat Res. 2015;8(3):149-57.

Houben AJ, van der Zander K, de Leeuw PW. Vascular and renal actions of brain natriuretic peptide in man: physiology and pharmacology. Fundam Clin Pharmacol. 2005;19(4):411-9.

Hsu JH, Liou SF, Yang SN, Wu BN, Dai ZK, Chen IJ, Yeh JL, Wu JR. B-type natriuretic peptide inhibits angiotensin II-induced proliferation and migration of pulmonary arterial smooth muscle cells. Pediatr Pulmonol. 2014;49(8):734-44. 
Lazar HL, Bao Y, Siwik D, Frame J, Mateo CS, Colucci WS. Nesiritide enhances myocardial protection during the revascularization of acutely ischemic myocardium. J Cardiac Surgery. 2009;24(5):600-5.

Lenting PJ, Christophe OD, Denis CV. von Willebrand factor biosynthesis, secretion, and clearance: connecting the far ends. Blood. 2015;125(13):2019-28.

Lerman A, Edwards BS, Hallett JW, Heublein DM, Sandberg SM, Burnett JC Jr. Circulating and tissue endothelin immuno reactivity in advanced atherosclerosis. $N$ Engl $J$ Med. 1991;325:997-1001.

Lerman A, Holmes DRJr, Bell MR, Garratt KN, Nishimura RA, Burnett JCJr. Endothelin in coronary endothelial dysfunction and early atherosclerosis in humans. Circulation. 1995;92(9):2426-2431.

Liu SQ, Yu YY, Xie HW, Yu K, Wang LX. Treatment with nesiritide, a recombinant B-type natriuretic peptide, reduces vascular remodeling following balloon-induced endothelial injuries in rabbits. Tohoku Exp Med. 2010;222(3):219-223.

Liu SQ, Xie HW, Yan HY, Lu YQ, Wang LX. Recombinant B-type natriuretic peptide nesiritide attenuates vascular remodeling by reducing plasma aldosterone in rabbits. Heart Lung Circ. 2012;21(9):551-555.

Manoury B, Montiel V, Balligand JL. Nitric oxide synthase in post-ischemic remodeling: new pathways and mechanisms. Cardiovasc Res. 2012;94(2):304-15.

Mannucci PM. Von Willebrand factor: a marker of endothelial damage? Arterioscler Thromb Vasc Biol. 1998;18(9):1359-1362.

Meyer AA, Kundt G, Steiner M, Schuff-Werner P, Kienast W. Impaired flow-mediated vasodilation, carotid artery intimamedia thickening, and elevated endothelial plasma markers in obese children: the impact of cardiovascular risk factors. Pediatrics. 2006;117(5):1560-1567.

Menon SG, Mills RM, Schellenberger U, Saqhir S, Protter AA. Clinical implications of defective B-type natriuretic peptide. Clin Cardiol. 2009;32(12):E36-41.

Pan Y, Zhu W, Ma J, Xin P, Han B, He Y, Wang Y, Peng T, Wei M. Therapeutic effects of continuous infusion of brain natriuretic peptides on postmyocardial infarction ventricular remodelling in rats. Arch Cardiovasc Dis. 2011;104(1):17-28.

Pauriah M, Khan F, Lim TK, Elder DH, Godfrey V, Kennedy G, Belch JJ, Booth NA, Struthers AD, Lang CC. B-type natriuretic peptide is an independent predictor of endothelial function in man. Clin Sci. 2012;123(5):307-12.
Perez AL, Grodin JL, Wu Y, Hernandez AF, Butler J, Metra M, Felker GM, Voors AA, McMurray JJ, Armstrong PW, Starling RC, O'Connor CM, Tang WH. Increased mortality with elevated plasma endothelin-1 in acute heart failure: an ASCEND-HF biomarker substudy. Eur J Heart Fail. 2016;18(3):290-297.

Plante E, Menaouar A, Danalache BA, Broderick TL, Jankowski M, Gutkowska J. Treatment with brain natriuretic peptide prevents the development of cardiac dysfunction in obese diabetic db/db mice. Diabetologia. 2014;57(6):1257-67.

Sun TW, Wang LX. Low levels of B-type natriuretic peptide predict poor clinical outcomes in patients with chronic and advanced heart failure. Medical Hypotheses. 2007;68(3):677-679.

Suzuki J, Isobe M, Morishita R, Nishikawa T, Amano J, Kaneda Y. Prevention of cardiac allograft arteriosclerosis using antisense proliferating-cell nuclear antigen oligonucleotide. Transplantation. 2000;70(2):398-400.

Volpe M. Natriuretic peptides and cardio-renal disease. Int J Cardiol. 2014;176(3): 630-639.

Wei TM, Zeng CL, Chen QY, Chen LP, Lu GX, Shi ZH, Lu CL, Wang LX. Systolic and diastolic heart failure are associated with different plasma levels of B-type natriuretic peptide. Int J Clin Pract. 2005a;59(8):891-894.

Wei TM, Zeng CL, Chen QY, Chen LP, Lu GX, Shi ZH, Lu CL, Wang LX. Plasma BNP Levels are determined by the severity of Ventricular Systolic Dysfunction but not the types of underlying Heart Diseases Acta Cardiol. 2005b;60(3):303-306.

Wei TM, Zeng CL, Chen LP, Chen QY, Zhao RY, Lu GX, Lu CL, Wang LX. Bedside tests of B-type natriuretic peptide in the diagnosis of left ventricular diastolic dysfunction in hypertensive patients. Euro J Heart Fail. 2005c;7(1):75-79.

Wei GL, Krasinski K, Kearney M, Isner JM, Walsh K, Andrés V. Temporally and spatially coordinated expression of cell cycle regulatory factors after angioplasty. Cir Res. 1997;80(3):418-426.

Yao HQ, Wang FJ, Kang Z. Effects of endovascular interventions on $\mathrm{vWF}$ and $\mathrm{Fb}$ levels in type 2 diabetic patients with peripheral artery disease. Annal Vasc Surg. 2016;33:159-66.

Received for publication on $22^{\text {nd }}$ July 2018 Accepted for publication on $23^{\text {rd }}$ October 2018 